\title{
Getting to Health through Integrative Practices
}

\author{
Farah MC Shroff* \\ University of British Columbia Faculty of Medicine, Department of Family Practice and School of Population and Public Health, Vancouver \\ $B C$, Canada
}

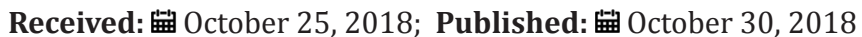

*Corresponding author: Dr Farah MC Shroff, University of British Columbia Faculty of Medicine, Department of Family Practice and School of Population and Public Health, Vancouver BC, Canada

\begin{abstract}
Traditional medical practitioners far outnumber practitioners of allopathic medicine in most parts of the South World. They are thus, de facto, the world's most popular form of primary care. This article discusses the re-emergence of traditional/integrative ${ }^{1}$ healthcare around the world. Within 'post'-colonial societies, traditional health knowledge has re-emerged in the context of nationalist struggles for independence and a growing interest in natural health care. As people of the South World ${ }^{2}$ and indigenous communities become more self-reliant, interest in indigenous health practices develops. Concomitantly, as critiques of allopathic medicine's side-effects develop, interest in natural and spiritual forms of healthcare grows. Those who can access allopathic care, however, almost always choose to blend it with traditional medicine. This article critically explores the fundamental concept of and the increasing popularity of integrative healthcare practices particularly within South World societies. We touch on the reintegration of traditional and modern health knowledge and how this trend is simultaneously occurring all over the planet. While colonialism negatively impacted the work of traditional medical practitioners (Shroff) [1], in contemporary times, many people are finding answers to modern problems in ancestral practices. It is challenging to piece together bits of verbal knowledge handed from one generation to the next so gaps in knowledge inevitably exist. Regardless, knowledge evolves, and changes are made to virtually all practices as a result. As new diseases and problems arise, wholistic health care is trying to adapt to these challenges. Blending the evolved practices of integrated healthcare with modern day conceptualizations of body and mind, today's wholistic health practitioners have a much better toolkit than they had in the past. This bodes well for health promotion, disease prevention, treatment, rehabilitation and palliation of societies around the world. In blending ancient and modern healthcare knowledge forms, population health status may benefit from the transformative potential of healing properties of plants, particular foods, water, spinal manipulation, acupuncture, the deep connection between mind, body and spirit, massage therapy techniques, and the salubrious effect of a true healer. This article will explore the international, interdisciplinary, historical and contemporary manifestations of wholistic thought forms.
\end{abstract}

The concept of wholism is defined in various ways. This article offers foundational understandings of this term from various parts of the world, illustrating the virtually universal, historical as well as contemporary nature of ideas such as interconnectedness, unity and oneness. Throughout human history, wholistic worldviews were dominant until the past 400 years or so when reductionist worldviews became prevalent. Currently, a revival of wholistic thought forms is taking place in many parts of the world. The purpose of this article is to sketch the landscape of wholistic philosophical foundations, discuss systems science in this context and apply these underpinnings to wholistic health. In addition, we discuss the importance of wholism and social justice for developing community health. Additionally, although we do not have space in this article to discuss it, we support efforts to regulate integrative health care for the purpose of protecting patients. We hope that this article will increase understandings of both the conceptual foundations of wholism as well as its South World applications to health. The article concludes with the recommendation that wholistic health-care practitioners take social inequities into account, so that integrative health care can become a means for individuals to take action for wellness as well as a means to create structural changes toward equitable resource distribution.

${ }^{1}$ The words integrative, natural, and traditional are used interchangeably in this article.

${ }^{2}$ South World is used here to encompass Latin America, Afrika, Asia, and the Middle East. We choose to spell Afrika with a K because we wish to acknowledge and embrace the spelling used by Afro-centric scholars. 


\section{Introduction}

Thousands of years old, traditional systems of health care blend mind, body and spirit. Healers who worked with plants, those who set bones, spiritual healers, birth attendants and others, were sought out by local people partly because of shared cultural worldviews. Despite European colonial invaders' attempts to destroy traditional medicine, its practitioners survived, and some are thriving today: serving $80 \%$ of the people of Afrika, $40 \%$ of China, $71 \%$ of Chile, and $70 \%$ in India [2,3] (Stanley 2011, WHO 2002). In some cases, people are choosing traditional medicine in conjunction with other systems of medicine and in other cases, traditional medicine is used on its own; sometimes traditional medicine is the only affordable option. Much of the time, people are choosing tradition medicines because they believe they are effective. In contemporary times, research efforts throughout the world are assisting the growth of tradition medicine. Organizations like Pro.Me.Tra (www.prometra. org) and FAPEG (Traditional Healers' Self-Proficiency Training) promote Afrikan traditional systems of medicine through cultural and scientific research and training. These organizations aim to train healers. They work towards effective wholistic treatments for headaches, chronic pain, depression, and other conditions.

\section{Charlatanism in the Practice of Traditional Medicine}

We would be remiss were we to ignore the fear-driven and lucrative business of pseudo-traditional healers. Confusing authentic traditional healers with those who profiteer from the vulnerability and illness of people is a big mistake. While we rebuke the unscrupulous practices of those charlatans, the rest of this article will not focus on them. Our interest is in finding ways to regain health through wholism and traditional knowledge for the benefit of people in the South World and beyond.

\section{Authors' Social Location}

I am a Parsi who was born in Nairobi, Kenya. Swahili and Kikuyu were two of my first languages and I also spoke English, Gujarati, and some Hindi as a child. I believe that one of the most powerful roads of liberation is via indigenous knowledge systems which teach us about our worldviews, various practices, and ourselves. It is through these ancient knowledge forms that we help to build peace and justice and we also can see the commonalities between our worldviews. My work has largely been on South Asian indigenous knowledge and the linkages that all forms of indigenous knowledge have with each other. I have a genuine desire to see wholistic health practices re-emerge in the modern world, blending old and new in a practical and powerful way to heal this planet. Wholistic health systems, in concert with allopathic systems, have the potential to effectively treat many illnesses. Besides working as a researcher and an educator, I am a teacher of yoga, meditation, dance, singing, martial arts and other creative wholistic expressions. In writing this article, my hope is to contribute, even in a small way, to health for all people. As a diasporic Parsi, I strive to be an ally to people of the
South World who are working towards better community health and social justice. I believe that Indigenous knowledge systems are interconnected and related to spiritual forms that will help the world to be healthier and more just. My interest in wholistic health has many roots. Wholistic health has tremendous healing potential and this has been proven in a myriad of peer-reviewed articles in medical journals, including systematic reviews (Mujahid et al.) [4]. I have personal interests for my own health and that of our family. In the early 1990s when I was preparing my PhD thesis on wholistic health care, relatively little peer-reviewed literature existed. Since then it has been very exciting to witness an explosion of literature in this field. This resurgence both in integrative practices and research is very promising for improving community health. Besides improved health, understanding and embracing wholism has potential for decolonizing the minds of the peoples of Afrika, Asia, Latin America, the Middle East and the Indigenous Peoples of the Americas and elsewhere. Wholistic health is part of a larger anti-racism and anti-imperialism project. In trusting Indigenous knowledge as scientific and salubrious, people begin to believe in themselves. Finally, when we embrace our cultural ways of knowing the world and our mind/body constitutions, we understand ourselves in a deeper fashion. Knowing ourselves is one of the most important tasks in life. I have been inspired by the brilliant work of Swami Vivekananda, Dr. Carole Yawney, Dr. Clem Marshal, Dr. Patricia Hill Collins and those who write about integrated healthcare. I have also been inspired by other liberation leaders such as Dr. Thomas Sankara, Dr. Bene Madanagu and others. From them, we learn about the importance of self-determination and freedom. Validating indigenous knowledge is part of the project for liberation. Amalgamating old and new knowledge forms has the potential to improve community health. This includes ancient knowledge emanating from traditional Afrikan societies, such as the importance of the ancestors, elders, language, greetings, heartto-heart communication and innumerable scientific advancements. These scholars and social actors have taken action to help people regain self- knowledge, self-love and power in the world. I am inspired by concepts of Kawaida, a philosophy which is pan Afrikanist and collectivist and its seven principles of Umoja (unity), Kujichagulia (self-determination), Ujima (collective work and responsibility), Ujamaa (cooperative economics), Nia (purpose), Kuumba (creativity) and Imani (faith), and other Afro-centric philosophical conceptualizations. I appreciate the sentiments behind the Swahili word for tradition and reason, Kawaidaexpounded by Maulana Karenga--because it exemplifies the libratory use of traditional arts and sciences for healing the modern world. Kawaida is much broader than just health and healthcare, it also embodies the philosophy of Afrika, the Mother Continent, seeking to heal her children around the planet. Dr. Maulana Karenga created the concept of Kawaida during the US Black Power struggles as a way of changing consciousness or empowerment. Afro-centric explanations of Kwanzaa also resonate. I denounce 
the brutality of colonial and neo-colonial, socio-cultural, economic and military attacks on South World people by Europeans, North Americans, Chinese, local elite imperialists, and I stand in solidarity with people around the world who are struggling for self-reliance, social justice, and peace, which are bedrocks for better health. This approach to traditional medicine acknowledges the tremendous healing potential of the spirit and the sagacious work done by those who are authentically connected to it. Those whose spiritual practices lead them to that profound sense of connection to all life are leaders in the creation of sustainable changes towards community health, human rights and peace.

\section{Principles of Wholism}

The English words health and wholistic are semantically related. They both stem from the same root word: The Anglo-Saxon words whole, hale, and holy (Pretorius) [5]. Despite the linguistic connection, the word wholistic is used in incongruent ways and has become an umbrella term that is used to encompass anything that is non-reductionist or dualist. We spell it as wholism, to accentuate the semantic connections of this word to the word "whole". In this article, the concept of wholistic health care will be used interchangeably with integrative medicine, traditional healthcare, alternative or complementary medicine and will be defined as approaches to well-being and treatment of illness that focus on the mind and body. Additionally, the term wholistic health care is used in this article to encompass self-care, practitioner-based care, and wholistic products. Wholistic self-care encompasses practices such as yoga, meditation, Tai Chi and Chi Gung. Wholistic care provided by professionals encompasses Traditional Chinese medicine, Ayurveda, Afrikan bone-setters, spiritual healers, traditional birth attendants, homeopathy, botanical medicine, therapeutic massage, and others. Products include herbs, potions, powders, tablets, pills and so forth. Wholistic schools of thought vary from region to region and throughout time, but ultimately, have more similarities than differences. A number of principles unite them. One principle they have in common is that entities and systems in the universe, including humans, are considered part of a unified whole that cannot be understood by the isolated examination of its separate parts (Dusek) [6]. These parts are actively interrelated, interlinked, interconnected, and dynamic. Wholistic worldviews do not focus exclusively upon the body or organism, but on the larger world and are often associated with spiritual or religious thought-forms. At the heart of wholism, there is an awareness of the unity and mutual interrelation of all things and events. All things are seen as interdependent and inseparable. This ultimate and indivisible reality is called Ubuntu in southern Afrika, Brahman in Hinduism, Dharmakaya in Buddhism, and Tao in Taoism. Shamans in Latin America also embrace parallel philosophical concepts. Since this reality transcends all concepts and categories, Buddhists also call it Tathata-Suchness (Deshmukh) [7], that Which Is, or Is-ness, the sum of all forms. According to Afrikan wholistic worldviews, for example, the cosmos is one spiritual totality. Spirit is not separate from matter, as everything is connected. In Afrikan wholistic thought, all things are considered to be related through one divine force (Asante et al.) [8]. They are alive, giving and receiving energy, with all life and matter created for a specific purpose. The concept of Ubuntu, for example has been translated as "I am what I am because of who we all are" (Gbowee L) [9] illustrating a collectivist cultural value which acknowledges the primacy of relationship. This also refers to kindness and other humanitarian values. Ubuntu is found in many Afrikan languages: Shona, Tswana, RwandaRundi, Kitara, Luganda, and others. In the Yoruba tradition, the Creator, Oludumare, is considered to be transcendent, exhibiting the quality of "atérerekáyé (that which spreads all over the world or who covers the whole world or makes the whole world feel its presence)" (Omosade) [10].

Indigenous philosophies are similar. Indigenous peoples see themselves as part of a Sacred Hoop or Circle of Life, not having control over it. This meaning they are careful to maintain a balance with life (Hunter et al.) [11]. Just as we impact the broad cultural climate in which we live, our physical, emotional, and psychological health is influenced by that very climate. Social harmony thus influences individual wellbeing in many Native Cosmo-visions. First Nations healers advise people to see everyone as a family member or friend, thus encouraging social integration (MehlMadrona) [12]. The Medicine Wheel, representing harmony and connectivity, takes this concept further. It represents all of creation: all planets, stars, peoples, animals, and plants. The Medicine Wheel is the basis of community health, with the circle symbolizing the cycles of seasons and of life, wholeness, and perfection. First Nations' healing circles, sweat lodge ceremonies and other healing rituals are generally performed in a circle. The circle emphasizes togetherness and community unity, without which the individual cannot be well. Prayer, dreaming, reflection, dialogue, talking circles and so forth, form part of the healing traditions of some North American Indigenous communities.

\section{Systems Science}

These ancient principles of interconnectedness and relationship are also present in some fields within contemporary science. During the past few decades, scientists from various disciplines, such as Ilya Prigogine, Erich Jantsch, Gregory Bateson, Humberto Maturana, and Manfred Eigen have developed emerging systems views of the world and made the study of living systems, organisms, social systems and ecosystems their focus. The systems view focuses on integration and relationships to see systems as interconnected wholes whose properties cannot be reduced into smaller units. Every organism, from the smallest bacterium to plants, animals and humans, are integrated and considered as living systems. Families and communities are also considered as systems. Gregory Bateson (1972), for example, was interested in 
studying patterns-from crabs to lobsters and orchids to humansand in seeing the interrelatedness of life forms. For hundreds of years, much of western science concentrated on isolating the world's basic building blocks. Now that this has been achieved to some extent, the systems approach emphasizes principles of organization creating a more ample understanding of matter from macro and micro-perspectives. Systemic properties are lost when a system is dissected, either physically or theoretically, into isolated elements. Although it is possible to discern individual parts in any system, the nature of the whole is different from the mere sum of its parts (Kineman JJ et al.) [13]. This understanding ties in very well with principles of wholism and wholistic health.

\section{The New Physics}

Connected to systems science, some physicists also make connections between their work and wholistic thought forms. Notable physicists such as David Bohm and Fritjof Capra emphasize the similarities between their theories of the indistinguishability between field, force, mind, and matter, with the spiritual traditions of Buddhism, Confucianism, Hinduism, Taoism and Afrikan traditional medicine systems. These scientists' work emphasizes the same notions as wholism; the whole is greater than the sum of its parts. The natural world interacts synergistically. It is thus not possible to fully understand systems by solely knowing the properties of their individual components-although it is useful to study individual components. Indeed, as stated by Capra, "the basic oneness of the universe is not only the central characteristic of the mystical experience, but it is also one of the most important revelations of modern physics. It becomes apparent at the atomic level and manifests itself more and more as one penetrates deeper into matter, down into the realm of subatomic particles" (Gaan N) [14]. The new physics thus emphasizes interrelation and the indeterminate, and probabilistic qualities of matter and energy. It also challenges components of the scientific method related to Newtonian mechanics, such as determinism and linear causality.

\section{Evolution in Allopathic Medicine}

Like systems scientists and the new physicists, some allopathic physicians are moving beyond these 'old' scientific paradigms in conceptualizing health issues (McQuaide M) [15]. While there are thousands of allopathic physicians whose work incorporates wholistic health, Deepak Chopra, MD, Andrew Weil, MD, and Paul Waako, MD, have gained great popularity. Their work has successfully bridged a gap between reductionism and wholism anddrawing from quantum mechanics theory-has conceptualized the importance of quantum or wholistic paradigms for health. These allopathic physicians with wholistic inclinations predict that sooner or later, allopathic medical science will catch up with the theoretical revolution in physics. As the interdependence of mind and matter is now firmly established in the model of reality used by contemporary physicists, these physicians assert that medical researchers ought to seriously take up the research challenge of analyzing how the mind and body interact. Many Canadian allopathic physicians are teaching (or referring) their patients meditation, breathing techniques based on pranayama (a yogic practice), relaxation and other aspects of wholistic practice. They are also open to sharing care with practitioners of Traditional Chinese Medicine and other wholistic health practices. Students in allopathic medical schools are also curious about wholistic practices.

\section{Wholistic Health-Applying these concepts}

Concepts of wholism find concrete application in systems of wholistic health promotion, disease prevention, treatment of illness and/or palliative care. What connects the diversity of these wholistic traditions is that without exception, they take into account mind, body, environment, and the interconnection between them. They recognize the interrelationship between human health and the social and physical environment. Wholistic health theory is posited on the notion that life force connects all that is alive in the universe, and that this energy is responsible for the life of all beings. There is no English word for this concept but in almost 50 languages around the world it has a name. It is called NTU in Bantu, Prana in Sanskrit, Chi in Chinese, and Mana in Hawaiian. NTU is that which gives us life, or is the vehicle of life, the cosmic breath, the rhythmic oscillation effective on all levels of conditioned existence. Restoring and keeping this life force flowing is one way of keeping people healthy. Wholistic health is typified by various characteristics such as the notion that health is a positive state, not merely the absence of disease, and that health is tied closely to familial, social, and cultural environments. Wholistic health care is also characterized by the belief that successful healing transforms the practitioner as well as the client and that healing includes a spiritual component in the etiology and treatment of illness. Wholistic healthcare theory understands malfunctions (illness) in the context of the social, cultural, and spiritual environment. Treatment of both body and mind are considered integral (Barnes) [16]. The body is understood in a unified manner within wholistic health perspectives. Injury to one part of the body may thus damage another, seemingly unrelated, part. Kidney malfunctioning, for example, may result from a damaged heart. If one part of the kidney is injured, such as one medullary pyramid, another medullary pyramid may take over its functions. Wholistic principles maintain that the body has an innate capacity to heal itself, and the role of the physician is to first, do no harm and secondly, to assist the body in its natural tendency toward balance. As mentioned above, however, allopathic doctors are increasingly using alternative medicine in their practices, and some allopathic doctors work with alternative practitioners or frequently refer patients to them. Functional medicine, a relatively new creation, applies a systems approach that engages both patients and practitioners in understanding genetics, environment and lifestyle factors in healthcare. Increasingly, nurses, midwives, physiotherapists and other healthcare practitioners 
also incorporate wholistic practices into their clinics. So wholistic practices are growing in various healthcare systems.

\section{Wholistic Health Care: A Growing Trend}

While allopathic medicine is useful for the treatment of acute emergency care needs, wholistic health care appears to be promising for chronic conditions and mental health care. These medical conditions constitute a majority of health problems; chronic diseases are leading causes of death and disability around the world (Palmer) [17]. Thus there is a critical need for multiparadigmatic, evidenced-based prevention, and medication for chronic diseases and mental illness. Moreover, the WHO estimates that by 2030 mental health disorders, topped by depression and anxiety, will be a leading cause of disability (WHO) [18]. This is partly why awareness for wholistic care in North America is growing among health professionals and the general public. In the United States for example, Americans spend up to 34 billion dollars per year on complementary alternative medicine (2015). Moreover 83 million U.S. adults are using some form of wholistic and alternative medicine (NCCAM) [19]. In Canada, that number is similar, with one study finding that $73 \%$ of Canadians have used some form of wholistic health care in their lifetime (Esmail) [20]. While studies measure different definitions of wholistic health and varying time periods, Canadians are increasingly using wholistic health care. The interest is in part due to the increasing dissent with the present system of medical care delivery. Some people, particularly women, prefer wholistic practitioners partly because of practitioner friendliness and interpersonal sensitivity [8,21]. This relatively egalitarian relationship is valued for many clients who have sought out wholistic practitioners. Fewer side effects, the perceived lack of harm from wholistic health care and the possibility of improved health are other reasons why Canadians are turning to wholistic healthcare practices (Quan) [22]. However, wholistic practices are virtually always accessed in conjunction with allopathic practices. In North America; very few people and practitioners, even those who are active proponents of wholistic care, use no allopathic medicine.

\section{Wholistic Health Care Critically Examined}

It is precisely because of their growth and interest that wholistic models also need to be considered critically. Most systems of wholistic health are overly concerned with the individual and her/his mind, body, and spirit, but rarely examine the health connections to the larger social world. This is probably the most astute criticism of wholistic health care. Most systems of health care, including wholistic ones, do not include social determination of health as a major component. This lack of attention to public health and the social determinants of health is a serious gap in wholistic healthcare practices. Furthermore, within many systems of wholistic medicine, patriarchal and classist overtones are apparent. In Chinese medicine, for instance, Yin traditionally means the shady side of a mountain, but is also related with femaleness sometimes, and is interpreted under a patriarchal lens. Thus, within this lens (and not all lenses), Yin and women are considered more negatively than Yang. For Taoists, there is no such thing as absolute moral judgments, with neither Yin nor Yang representing good or bad [5]. While this reasoned view (which states that neither Yin nor Yang is good or bad) is probably the original medical understanding, oppressive social and economic structures have affected modes of thinking. Most likely, the original writings were not corrupted by hierarchical social structures, but have over time created division within their teachings. This is mostly likely a result of the intricately intertwined nature of medicine and politics. Upper class, patriarchal and heterosexist interpretations of wholistic health concepts flourish in the literature but are misinterpretations of original teachings $[23,24]$. Furthermore, wholism has been embraced by several groups, including those who serve non- wholistic ends. Amongst them are "new age" entrepreneurs who are profiting from the commodification of wholistic health, including shamanic healing, hypnosis, trance work and so forth. These practitioners, who claim to be wholistic, profit from the work of others and from the teachings they have gained from South World knowledge forms, without crediting the original sources. They may claim to 'westernize' wholistic practices in order to lure customers who know very little about the origins of wholism. They may also excuse sexist, heterosexist, classist behaviour in the social organization of their work, on the grounds that the culture from which it comes is based on oppressive practices. This kind of racist appropriation and misrepresentation of wholism is dangerous, as are the claims made by practitioners masquerading as wholistic healers. They state that they can miraculously cure diseases in order to lure vulnerable and ill people into paying large sums of money for unproven therapies. Some aspects of these therapies are problematic when they fail to take into account power differences and their grafted relationship with race, class, gender, sexual orientation, ability, age and so forth. Some, such as Louise Hay, go as far as to suggest that people are $100 \%$ responsible for creating their experiences (1984: xiii). This completely negates the existence of hierarchies such as imperialism, racism, patriarchy, heterosexual dominance and so forth. While it is pleasant to entertain the thought that individuals who create peace and harmony in their lives will have no (health) problems, it defies the experiences of many of us. There is always the danger of simplifying health and healing to a point where power relations are not taken into account. Unfortunately, this simplistic type of analysis pervades the new age movement's rhetoric, which results in various forms of "victim blaming" (Crawford) [25]. While it is true that the new age movement emphasizes fitness, wellness, prevention and risk reduction, all while downplaying the vast and ambiguous external forces that influence health, we must be cautious not to confuse new age entrepreneurs with wholistic health practitioners. 
The critique that wholistic health provides an individualistic solution to problems of health by changing the individual rather than the social causes of illness rings true. Plus, the victim- blaming ideology promoted by some wholistic health care providers shifts the burden of blame to the individual rather than the social context (Crawford) [25]. Yet this critique applies to allopathic medicine as well. Allopathic medicine does not encompass a social and political view of the determinants of health either. Public health, the humanitarian branch of allopathic medicine, is poorly funded and often neglected. Neglecting public health practices in most wholistic health systems is not a solid enough argument to dismiss wholism. It is, however, combined with the above arguments of appropriation and class privilege, a solid basis for dismissing the new age movement as opportunistic. Supporting well developed public health practice in all systems of medicine is a worthy goal. Complementary public health approaches to improving health for all will make significant impacts on all systems of health care.

\section{Closing Reflections}

The concept of wholism is international and ancient, stemming, as does all knowledge, from the Mother continent--Afrika. Crossing countries and historical periods, wholistic concepts and health practices based on these thought forms flourished for centuries but have declined over the past 500 years or so under European colonialism. European domination of the planet brought with it reductionism, dualism and their off-shoot, allopathic medicine. Currently there is a global re-emergence of wholistic thinking and wholistic practices, rarely framed within a libratory lens and embodied by concepts such Kawaidaa. This article analyzed the historical as well as contemporary basis of wholism as interconnectedness, unity and oneness, and its application to wholistic health care. Neither the allopathic nor the wholistic model of care attend to social inequities, yet wholistic practices generally take into account the many facets of the individual-emotional, social, mental, and spiritual. It is partly for its attention to emotional and spiritual aspect of health that wholistic care is popular. However, wholistic health care can be improved, and serve the needs of more people if race, class, and gender analyses were taken into account. The peoples of the South World still rely quite heavily on traditional systems of medicine and in many cases, this is because of its accessibility, financial and culturally. Deepening our understanding of the impact of social inequities on an individual's health will contribute to more efficient and just (wholistic) healthcare systems. When wholistic practices are joined with social justice approaches to working with communities, population health status promises to improve. This has been demonstrated in Thailand, Kerala, India, Brazil, Cuba and elsewhere. Moreover, when people's health care reflects their worldview, communities deepen their understanding of who they are-improving self-knowledge and pride. Major institutions are currently studying wholistic practices and products, including herbal remedies, bodywork, meditation, dietary changes and many others. Various studies, and some systemic reviews, are available on almost every type of wholistic practice, and some show promising results [26,27]. Working together, there is great potential for wholistic health care and allopathic medicine to improve population health [2834]. Allopathic medicine has made great advances in population health, particularly in emergency and acute care. Combining all the world's systems of medicine and scientifically choosing those which have the best health outcomes-the world has the potential to truly heal. If practitioners were to also take social inequities into account, this integrative health care could truly become a means for individuals to take action for wellness as well as a means to create structural changes toward equitable resource distribution. I have written elsewhere (Shroff, 1996) about a health care system that incorporates public health approaches and integrates best practices from multiparadigmatic medical systems. This article also reviewed the interdisciplinary nature of the concept of wholism, illustrating the philosophical and scholarly unity in the notions of unity and oneness, interconnection and inseparability of mind and body. Modern physics, particularly quantum mechanics, is at the forefront of the scientific frontier that has arrived at the same conclusions as philosophical ideas from Afrikan, Asian and other Indigenous cosmologies. Systems science, an interdisciplinary enterprise, is also part of this movement away from a reliance on reductionist thinking [35-39]. Given that the basis of wholistic philosophy is unity and oneness, a health care system that incorporates the most effective aspects of various systems of medicine would have powerful potential to improve population health on many levelsprofoundly embracing the concept of Ubuntu, which has often been summarized in the expression "umuntu ngumuntu ngabantu", meaning that a person is a person through persons (Ogude) [40].

\section{Acknowledgment}

I would like to thank my research assistant, Dr. Ayham Maatouk, for his help with the citations and proofreading of this chapter. It was fun to work with him on it.

\section{References}

1. Shroff F (2007) Power Politics and the Takeover of Wholistic Health in North America: An Exploratory Historical Analysis.

2. Stanley R (2011) Recognition and respect for African traditional medicine. International Development Research Centre.

3. WHO (2002) WHO Traditional Medicine Strategy: 2002-2005.

4. Asante MK, Mazama A (2009) Encyclopedia of Afrikan religion. Thousand Oaks, Sage Publications, CA, USA.

5. Mujahid M, Hussain T, Siddiqui HH, Hussain A (2016) Evaluation of hepatoprotective potential of Erythrina indica leaves against antitubercular drugs induced hepatotoxicity in experimental rats 8(1): $7-12$.

6. Pretorius SP (2009) Is "divine healing" in the "Faith Movement" founded on the principles of healing in the Bible or based on the power of the mind? HTS Teologiese Studies/Theological Studies 65(1): 1-7. 
7. Dusek V (2006) Philosophy of technology: An introduction. Hoboken Wiley-Blackwell, New jersey, USA, pp. 244.

8. Deshmukh VD (2006) Neuroscience of meditation. The Scientific World Journal 16(6): 2239-2253.

9. Gbowee L (2010) It's Time to End Afrika's Mass Rape Tragedy.

10. Omosade Awolalu J (1996) Yoruba Beliefs and Sacrificial Rites. Brooklyn, NY: Athelia Henrietta Press, Inc, New York, US.

11. Hunter LM, Logan J, Goulet JG, Barton S (2006) Aboriginal healing: Regaining Balance and culture. J Transcult Nurs 17(1):13-22.

12. Mehl-Madrona L, Mainguy B (2014) Introducing Healing Circles and Talking Circles into Primary Care. The Permanente Journal 18(2): 4-9.

13. Kineman JJ, Kumar AK (2007) Primary natural relationship: Bateson, Rosen, and the Vedas. Kybernetes 36(7/8): 1055-1069.

14. Gaan N (2005) Relevance of environment: a critique on international relation theories. Kalpaz Publications, Dehli, India.

15. McQuaide M (2005) The rise of alternative health care: a sociological account. Social Theory \& Health 3: 286-301.

16. Barnes P, Powell Griner E, McFann K, Nahin R (2004) Complementary and Alternative Medicine use among adults: United States, 2002. Seminars in Integrative Medicine (343): 1-19.

17. Palmer Sushma (2009) Global Health in Transition. Center for Communications, Health \& the Environment (CECHE) Washington DC USA.

18. WHO (2011) Global burden of mental disorders and the need for comprehensive, coordinated response from health and social sectors at the country level. Executive Board. $130^{\text {th }}$ session. Provisional agenda item 6: 2 .

19. NCCAM (2011) Complementary and Alternative Medicine: What People Aged 50 and Older Discuss With Their Health Care Providers. AARP and National Center for Complementary and Alternative Medicine Survey Report.

20. Esmail N (2007) Complementary and alternative medicine in Canada: trends in use and public attitudes, 1997-2006. The Fraser Institute, Vancouver, Canada.

21. Kelner M, Wellman B (1997) Healthcare and consumer choice: medical and alternative therapies. Social Science \& Medicine 45(2): 203-212.

22. Quan H, Lai H, Johnson D, Musto R (2008) Complementary and alternative medicine use among Chinese and white Canadians . Can Fam Physicians 54(11): 1563-9.

23. Liao Y (2006) Traditional Chinese medicine. Beijing: China Intercontinental Press.

24. Lad V (2006) Textbook of Ayurveda: A Complete Guide to Clinical Assessment, Volume 2, Albuquerque, NM: Ayurvedic Press.
25. Crawford R (2006) Health as meaningful social practice 10(4): 401-420.

26. Santesso N, Wieland LS (2016) A Summary of a Cochrane Review: Acupuncture for the prevention of tension-type headache. Eur J Integr Med 8(4): 324-325.

27. Wang J, Burke A, Tsoh JY, Le G, Wong C, et al. (2014) Exploring a Culturally Relevant Model of Cancer Prevention Involving Traditional Chinese Medicine Providers in a Chinese American Community. Eur J Integr Med 6(1): 21-28.

28. Ventegodt S, Merrick J (2009) Meta-analysis of positive effects, side effects and adverse events of holisitic mind-body medicine (clinical wholistic medicine): experience from Denmark, Sweden, United Kingdom and Germany. Int J Adolescent Med Health 21(4): 441-456.

29. Charles O Okoli, Peter A Akah, Nkemjika J Onuoha, Theophine C Okoye, Anthonia C Nwoye, et al (2008) Acanthus montanus: an experimental evaluation of the antimicrobial, anti-inflammatory and immunological properties of a traditional remedy for furncles. BMC Complement Altern Med 68: 27.

30. Schulzke J, Andres S, Amasheh M, Gunzel D(2011) Anti-diarrheal mechanism of the traditional remedy Uzara via reduction of active chloride secretion. PLoS One 6(3): pp. 18107.

31. Campbell Tofte JI, Molgaard P, Josefsen K, Abdallah Z, Hansen SH, et al. (2011) Randomized and double-blinded pilot clinical study of the safety and anti-diabetic efficacy of the Rauvolfia-Citrus tea, as used in Nigerian traditional medicine. J Ethnopharmacol 133(2): 402-411.

32. Capra F (2002) The Hidden Connections: A Science for Sustainable Living. Doubleday, New York, USA.

33. Dusek V (2006) Philosophy of technology: an introduction. Hoboken, Wiley-Blackwell, New jersey, USA, pp. 244

34. Hamza N, Berke B, Cheze C, Le Garrec R, Lassalle R et al. (2011) Treatment of high-fat diet induced type 2 diabetes in C57BL/6J mice by two medicinal plants used in traditional treatment of diabetes in the east of Algeria. J Ethnopharmacology 133 (2): 931-933.

35. Hay L (1984) You Can Heal Your Life. New York.

36. Healey R (2009) Wholism and nonseparability in physics. The Stanford Encyclopedia of Philosophy.

37. Evaluation of hepatoprotective potential of Erythrina indica leaves against antitubercular drugs induced hepatotoxicity in experimental rats. J Ayurveda Integr 8(1): 7-12.

38. Kheel M (1989) from healing herbs to deadly drugs: Western medicine's war against the natural world. In J Plant (Ed.), Healing the Wounds: The promise of ecofeminism pp. 96-111.

39. Knutson A (1961) Psychological basis of human behavior. American Journal of Public Health 51(7): 1699-1708.

40. Ogude J (2017) The Meaning and Value of Ubuntu in Human and Social Development in Africa. Templeton World Charity Foundation.

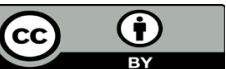

This work is licensed under Creative Commons Attribution 4.0 License

To Submit Your Article Click Here:

Submit Article

DOI: 10.32474/OAJCAM.2018.01.000112

\section{OAJCAM}

Open Access Journal of Complementary \& Alternative Medicine

\section{Assets of Publishing with us}

- Global archiving of articles

- Immediate, unrestricted online access

- Rigorous Peer Review Process

- Authors Retain Copyrights

- Unique DOI for all articles 